\title{
Application of Interactive Multimedia-Internet- Based Teaching System in College English Teaching
}

\author{
http://dx.doi.org/10.3991/ijet.v8i3.2690 \\ Zhang Wenming, Zhang Erwen \\ Anhui Polytechnic University, Wuhu, China
}

\begin{abstract}
-this paper aims to advocate the application of interactive multimedia-internet-based teaching system (IMITS) in college English teaching in Chinese colleges and universities. Based on a general analysis of the status quo of college English teaching in China nowadays, the theoretical base and construction principles of IMITS teaching are introduced, which is followed by a detailed elaboration on the actual utilization of IMITS in college English teaching and its advantages. At the end of this paper, some existing problems of IMITS teaching are exposed and the corresponding strategies are proposed to perfect the effects of IMITS in college English teaching.
\end{abstract}

Index Terms-multimedia, internet, autonomous learning, college English teaching.

\section{INTRODUCTION}

English, as a discipline, has long been a compulsory course in Chinese colleges and universities. College English Teaching (abbreviated as CET hereafter), as teachercentered and aided by traditional teaching tools like textbooks, blackboard, chalks and tape recorders, had almost remained the same by the end of last century. However, from 1999, with the tremendous expansion in enrollment, which led directly to the scale-up of college English class, the disadvantages of traditional CET mode has become more and more apparent, which were mainly shown in the following aspects: first, it outweighed teaching over learning and neglected the central position and individual difference of students [1]; second, students' ability of autonomous learning was generally low[2]; third, students had few chances to participate in any kind of classroom activities[3]. Thus, the reform in traditional CET mode has been urgently called for.

In 2001, Ministry of Education of China launched the reform in CET and in 2007, College English Curriculum Requirements (abbreviated as Requirements hereafter) was drawn up to provide colleges and universities with the new guidelines for English instructions to non-English majors, in which it was formulated that "In view of the marked increase in student enrollments and the relatively limited resources, colleges and universities should remold the existing unitary teacher-centered pattern of language teaching by introducing computer-and-classroom-based teaching models. The new model should be built on modern information technology, particularly network technology, so that English language teaching and learning will be, to a certain extent, free from the constraints of time or place and geared towards students' individualized and autonomous learning"[4]. Obviously, Requirements encourage a brand-new teaching mode which is based on multimedia and internet technology, and advocate the individualized and autonomous learning of students.

However, 5 years after the implementation of Requirements, the effects of CET turn out not to be as satisfactory as we've expected. With great advancement in teaching facilities and abundance in learning resources on the internet, students' ability in individualized and autonomous learning is not enhanced as Requirements aim to. Without a necessary guidance, students waste too much time in things irrelevant to English study when they browse the internet [5]. Autonomous learning of students is by no means self study, which should involve the participation of teachers and a sound teaching system [6]. Therefore, to make full use of modern information technology applied in CET, an interactive multimedia-internet-based teaching system (abbreviated as IMITS hereafter) should be built to guide students in their autonomous learning.

This paper, in view of the above-mentioned situations in college English teaching, firstly introduces constructivism as the theoretical base of applying IMITS in teaching and the construction principles of IMITS, then elaborates on the actual utilization of IMITS in college English teaching and its advantages, which is followed by a revelation of some existing problems, for which, some corresponding strategies are proposed to further perfect IMITS teaching at the end of this paper.

\section{CONSTRUCTIVISM}

Constructivism, firstly proposed by Swedish scholar Jean Piaget, emphasizes the positivity of recognition, which takes learning as a process of constructing knowledge. Learners are not passive receivers of exterior stimulus; instead, based on their previous experiences, learners will initiatively choose and process the exterior information and, through their interaction with teachers and other learners, finish the process of knowledge construction by themselves. Constructivism holds studentcentered view and takes situation, coordination, interaction and resources as the basic elements in learning environment [7]. It is believed that knowledge is not acquired by teachers' instruction, but through meaning construction when learners, under certain social and cultural background, are aided by teachers, peers and parents, and some necessary learning materials like textbooks, videos, computer software and web information, etc..

The major reason why constructivism can become the theoretical base of IMITS teaching is that constructivism 
values the hosting role of students in the process of recognition, which facilitates the formation of students' autonomous learning and their comprehensive development [8]. Besides, the characteristics of IMITS teaching call for constructivism as its theoretical base. IMITS guarantees students' autonomous learning with an open and real learning environment. The booming multimedia and web technology endows the learners with a chance for autonomous learning at almost any time or place [9]. During the process of students' autonomous learning, the view of constructivism on learning is supported by powerful technology and examined by IMITS teaching.

From what was discussed above, it can be concluded that constructivism, as the theoretical base of IMITS teaching, can help IMITS teaching exert its advantages so as to achieve better teaching effects.

\section{CONSTRUCTION PRINCIPLES OF IMITS}

IMITS should have such characteristics as long distance, interaction, flexibility and self organization. Therefore, to construct an IMITS, three principles should be observed.

\section{A. Student-Centered Principle}

Since the function of IMITS is to assist students in their autonomous English learning, the design of any module in an IMITS should take the participation of students into consideration and aim to provide students with a better learning environment that features varieties of learning tools, rich learning materials and real or non-real time interactions, etc. [10].

\section{B. Open Principle}

As IMITS is supposed to complement classroom teaching by making good use of the after-class time of students, it should be of user-friendly design. First, an IMITS should be open to students at any time or place, so that students can utilize IMITS in their learning with no spatiotemporal limitations; second, an IMITS should not be a close system itself, students are able to move outside their learning environment and visit other sites on the internet.

\section{Individualized Principle}

Since IMITS is designed to serve students of different kinds, it should consider the differences in students' types, personalities and learning speeds, and provide ranked learning modules so as to satisfy students' demands for individualized learning, which was described by Shunk \& Zimmerman as "learners have more freedom to decide why to learn, what to learn, when to learn, where to learn, with whom to learn and how to learn".

\section{UTILIZATION OF IMITS IN CET}

One of the major contents of college English teaching reform is the implementation of teaching mode based on multimedia and internet [11]. In order to assist English teaching, after a thorough investigation into different IMITS software available in the market, our university bought an IMITS developed by Qinghua Education Online in 2009. This system is mainly composed of two interfaces: teacher's interface and students' interface on which the menus are almost the same. After three years of operation, it has been discovered that the menus with highest using frequency are teaching material, course fo- rum, course exercise, teaching mailbox and online testing, a detailed analysis of which will be made respectively as follows:

\section{A. The Uploading Of Teaching Material Enriches The Learning Resource For Students}

By uploading the teaching courseware onto teaching material page for students' free browsing, teacher can save a lot of time in classroom teaching in writing on the blackboard or waiting for students to take detailed notes, which can be made use of to broaden the teaching contents and convey abundant information to students. Besides teaching courseware, teacher can also choose some relevant resource from the internet with reference to the topic of the teaching unit for students' self-study after class. For example, teacher can download the latest authentic audio material so that students can improve their listening ability and enlarge their knowledge by listening to these up-to-date news; teacher can also make use of those published video material for English learning and relevant websites, so as to provide students with vivid learning resource and pleasant learning environment [12].

\section{B. Course Forum Provides Students With A Chance To Speak English After Class}

Course forum is a platform for free discussion among students. Teacher can paste some hot topics on the forum so that students can express their opinions freely as long as the opinions are delivered in English, or teacher can paste some controversial issues and organize students to have debates on those issues. Besides, students can also make use of the forum to discuss the problems they met in study or life with other students, for example, one student once consulted with others on how to spend the spare time appropriately, which was responded by different answers. Some students shared with others their experience of visiting the welfare house and called for more students to join them; some students who are far away from their home expressed their homesick feelings in sentimental tone; while some others recommended the good movies or books they had recently seen. Besides, teachers are also supposed to get actively involved in the discussion by giving students appropriate comments or encouragement, inspiring students' enthusiasm in participation and maintaining the smooth development of communication. One of the important principles for IMITS teaching is to increase the participation of students in learning by means of teacher's involvement [13]. The implementation of course forum provides students with a chance not only to practice their oral English after class, but also to facilitate their mutual understanding and help them to find friends with common interests.

\section{Web-Based Course Exercise Enriches The Forms Of Exercise}

The traditional English exercises are mainly translation and writing, however, the web-based course exercise makes practice of listening and speaking possible. In the column of course exercise, the teacher can upload a section of English interview audios, then raise several questions to the students. Or he can upload some clips of movies, asking the students to write out the dialogues between characters in the movies and imitate the native English expressions. In this way, the forms of exercises are greatly enriched, which ensures students' ability of listening, 
speaking, reading, writing and translating are all practiced and improved.

\section{Teaching Mailbox Facilitates The Prompt Response To Students' Questions}

Some students, when they meet some problems in their study or life which they think inappropriate to ask their teachers face to face, can choose the teaching mailbox to ask for prompt help to their teachers who are supposed to give their advices with great patience. Or students can raise some suggestions to their teachers by mail, which help the teachers to know their students' need and perfect their teaching methods, thus ameliorating the relationship between teachers and students.

\section{E. Online Testing Helps Check The Learning Effects Of Students Promptly}

In the column of online testing, teachers can design a testing paper with reference to the unit they are teaching, and students are asked to finish the test within a limited time and on their own. In this way, the learning effects of students are checked promptly. The scores of students can be derived from the system directly by a score sheet, and such items as the passing rate and average score are clearly demonstrated, which not only saves a lot of time otherwise spent testing the students in class, but also avoids the trouble teachers might have when they conduct the statistic analysis on the testing scores.

Besides the above-mentioned five functions which have the highest using frequency, In IMITS, there are still some other menus practical in the daily teaching, for example, curriculum introduction, academic calendar and teaching syllabus, etc.. The availability of these menus can convey such information as teaching arrangement, teaching plan and teaching activities to the students, so that they can know clearly the cultivation objective, teaching method and teaching plan of their courses and arrange their learning progress accordingly.

\section{AdVANTAGES OF IMITS TEACHING}

Based on three years of applying IMITS to college English teaching in our university, some advantages of IMITS teaching have been found, which are demonstrated as follows:

\section{A. Stimulating Students' Learning Interest}

In the traditional college English class, what teachers can use are just one blackboard, one chalk and one textbook, which is thought to be monotonous in teaching methods, and leads to the passive acceptance of information with low interest for students. However, vivid, intuitional and interface-friendly as it is, IMITS teaching can provide an interactive learning environment for students and stimulate their learning interest by multi-sensory stimulus from abundant pictures, words, voices and videos.

\section{B. Reducing Students' Learning Pressure And Anxiety}

According to theories of second language acquisition, the emotional anxieties of learners are much likely to influence the output of language. In the traditional college English class, due to the differences in the learning levels among students, some students are so worried about making mistakes and being teased that they dare not to speak in public. However, communications through IMITS can reduce students' pressure and tension to some degree, enabling them to think at leisure and express their opinions fluently. And they won't flush when making mistakes The comfortable learning environment provided by IMITS helps students with the cultivation of learning positivity.

\section{Increasing Students' Opportunity For Language Practice}

In the traditional college English class, due to the limited time, the opportunity for students to express their opinions in English is severely restrained. However, various activities like English conversation, English writing and other kinds of web exercises provided by IMITS can give a lot of opportunities to students to practice their English, which not only improves the fluency and authenticity of their English expression, but also enhances their confidence in learning and practicing English.

\section{Facilitating The Development Of Students' Autonomous Learning}

In IMITS, the learning resources provided by teachers are so abundant that students can actively choose the learning contents and learning strategies most suitable to themselves, shift from one topic to another and browse any language point in accordance to their interest and learning level. Meanwhile, during the process of choosing learning contents and constituting learning schedules, students' analytic ability, decisive ability, inductive ability and that of choosing learning materials are being practiced, which eventually leads to the improvement of their autonomous learning.

\section{E. Increasing The Emotional Exchange Between Teachers And Students}

Through IMITS, teachers and students can carry out instantaneous and mutual communication. On one hand, teachers can process the problems found in their class teaching and feed them back to their students promptly; on the other hand, students can also convey the problems in their study or life to the teacher for on-line answer or help. In this way, the emotional exchange between teachers and students are greatly increased, which definitely enhances the mutual understanding and leads to a harmonious relationship between them.

\section{PROBLEMS OF IMITS TEACHING}

Along with the above-mentioned advantages of IMITS teaching, some existing problems of IMITS teaching have also been found during the three years of applying IMITS in college English teaching in our university, which, as demonstrated below, are categorized in four aspects:

\section{A. Web Learning Environment}

Shortage of web facilities: According to a survey recently conducted among non-English major freshmen and sophomores in our university, $71 \%$ of them don't have a computer and $74 \%$ of them don't have access to the internet in their dormitories, which makes them go nowhere but the autonomous learning center to log on IMITS. However, the facilities in the autonomous learning center of our university and the time arrangement can not fully satisfy the learning demands of students. Shortage of web facilities is a major factor in restraining students from convenient use of IMITS for their autonomous learning, 
which is a universal phenomenon in most of China's universities and a fact not supposed to be changed in a short time.

Two-bladedness of web learning: While logging on IMITS for autonomous learning, many students have been found to play games, chatting with friends or just download answers directly from the web. Along with the abundant learning resources provided by IMITS, there are also a lot of resources of entertainment and games. The twobladedness of web learning raises such questions as how to improve the self-discipline of web learners and how to carry out interactions between teachers and students, which are new challenges for both teachers and students at the era of information.

\section{B. Teaching Administration}

During the three years of applying IMITS in college English teaching in our university, no web teaching training for teachers has been organized, no speciallydesignated person claims responsible for the administration of IMITS, and no surveillance on the quality of students' autonomous learning or assessment on the effect of teachers' web teaching has been established, which reveal the insufficiency of web teaching administration in our university. It should be admitted that how to perfect the teaching administration of IMITS has become a crucial issue for the smooth operation of web autonomous learning.

\section{Teacher Factor}

Web skill of teachers needs to be improved: It has been revealed by a questionnaire that $5 \%$ of teachers don't know how to browse the website, $42 \%$ don't know how to download files from the internet, the ratio of teachers who don't know how to send or receive emails and how to search for information is $39 \%$ and $42 \%$ respectively, and $68 \%$ of teachers don't know how to upload files to the internet. All the data mentioned above reveals that the information quality of teachers needs to be improved urgently so as to match the present information age.

Teachers' concept needs to be altered: The concept of teachers on teaching decides their teaching behaviors. Judging from the times of teachers logging on IMITS, their response to students' questions and the status quo of teachers uploading teaching materials on the system, it can be concluded that many teachers still weigh the teaching of English knowledge more than students' ability of autonomous learning. Only when they alter their teaching concept and actively get involved in the interaction with students in IMITS, can the system fully exert its full effect to improve students' ability of autonomous learning.

\section{Student Factor}

Information quality: Information quality is the prerequisite for students' web autonomous learning, which includes information immunity ability, information cooperation ability and ability of using information tools. However, as was discussed above, many students are playing computer games or doing other things irrelevant to English learning after logging on IMITS, which means they lack information immunity ability; besides, in IMITS, interaction among students is quite rare, which means their information cooperation ability needs to be improved; and it was indicated by the questionnaire that about $10 \%$ of students can not use various information tools fluently.
All the above-mentioned facts reveal that the information quality of students needs to be greatly enhanced.

Autonomous learning strategies: It has been pointed out by Wen Qiufang that under the same learning condition, learning strategy decides the effect of English learning. And it is the key to success to adjust the learning strategy consciously [14]. However, according to our investigation, $25 \%$ of students have no plans for web learning, 31\% don't have cognitive strategy; 53\% lack metacognitive strategy; and $86 \%$ lack the strategy of selfdiscipline management, which indicate that the autonomous learning strategies of college students are quite poor and thus unavoidably influence the effects of web autonomous learning.

Autonomous learning consciousness: Compared with the poor autonomous learning strategies of students, what has been revealed in the results of our questionnaire is another more severe fact: the lack of autonomous learning consciousness among students. For most college freshmen, they tend to keep their formal learning ways in high school to study English, which, as passive and teachercentered, is in sharp contrast with the spirit of web autonomous learning. Therefore, the cultivation of autonomous learning consciousness among students becomes a crucial factor to carry out the practice of IMITS in college English teaching.

\section{CORRESPONDING PROBLEM-SOLVING STRATEGIES}

As was discussed above, the existing problems of IMITS in college English teaching are mainly manifested in the four aspects: web, teaching administration, teacher and student, regarding to which, some corresponding problem-solving strategies will be proposed as follows:

\section{A. Strategies Concerning Web}

To improve web autonomous learning environment: Unavailability of web access and restricted use of autonomous learning center are two major factors in restraining students from convenient use of IMITS for their autonomous learning, which is a universal phenomenon in most Chinese universities and hardly changed in a short time. Therefore, how to make full use of the autonomous learning center under the present condition is a major issue regarding students' autonomous learning.

At present, the autonomous learning center of our university is only open during the work hours. In order to increase the time of autonomous learning for students, it is strongly recommended that the open hour of autonomous learning center be expanded to those off-work hours in the evening and at weekends, besides, during summer and winter vocations, the autonomous learning center should also provide access to those students who'd like to log on IMITS for learning English at home. In this way, the autonomous learning center can exert its maximum function in assisting students' autonomous learning.

To enhance multi-dimensional interaction: The twobladedness of the web indicates that students might do something irrelevant to English study when logging on IMITS, which raises a question to all teachers and education administrators as how to guarantee the effects of students' web autonomous learning. Since it is undesirable and almost impossible to monitor their web learning, the answer lies in only one way, i.e. to enhance multidimensional interaction, which means the interaction be- 
tween students and computer, between teachers and students and among students under web learning environment. Only in this way can students feel actively involved in English learning and find fun consequently. To ensure the above-mentioned three ways of interaction, more abundant learning resources, more frequent participation of teachers and more interactive modules in IMITS are thus required.

\section{B. Strategies Concerning Teaching Administration}

To constitute the teaching plan for English autonomous learning: With reference to Requirements, our university should establish the teaching goals of English curriculum and teaching requirements on English web curriculum, and constitute the teaching plan for English autonomous learning from the perspective of web curriculum description, requirements for teachers' web tutoring, arrangements for web teaching, administration on web learning credits, assessments on web teaching and progress of students' web autonomous learning.

To include English web learning in credit assessment: The present credit system is composed of mid-term examination, final examination and classroom attendance, which needs to be reformed so as to include English web learning. Only in this way can web English learning be assured from the level of administration.

To quantify web teaching: Students' autonomous learning is by no means their own job, which calls for teachers' participation. In order to get teachers actively involved in IMITS, our university should quantify teachers' web teaching from the perspective of teachers' concept on web teaching, their skills and frequencies of web communication with students.

To assess the quality of web autonomous learning: It should be stipulated that teachers and administrators of college English teaching carry out regular or irregular examination on the teaching and learning of English through IMITS; and communications between teachers and students should be organized from time to time so as to eliminate any factors that might influence the effects of English web autonomous learning.

\section{Strategies Concerning Teacher}

To renew teachers' concept and change their role: The key to teaching reform is to change the role of teacher in teaching. Teachers are supposed to free themselves from the teacher-centered, spoon-fed teaching concept, and their roles should be changed from instructor, judger and examiner to guider, partner and participator. As the builder and governor of IMITS, teachers should fulfill such jobs as to assign the learning tasks, examine the effect of learning, find any problems in the teaching progress and interact with students as much as possible. Only when teachers are actively involved in the platform of IMITS, can students be more voluntarily emerged in their autonomous learning.

To improve the information quality of teachers: With the booming of information technology, teachers should be well acquainted with information quality so as to guide students in their autonomous learning. The information quality of teachers should include such aspects as follows: firstly, they know how to make full use of modern education technology in their teaching design and create a sound learning environment for the learners; sec- ondly, they can apply web information and virtual libraries in their web teaching; thirdly, they are capable of combining modern information technology and college English curriculum by using good teaching software and abundant web teaching resources.

To promote the surveillance level of teachers: It becomes a realistic issue for all universities to enhance the surveillance of college English web autonomous learning. For teachers, too much help to students will kill the positivity of learners, while no surveillance will lead to the low effectiveness of autonomous learning. To promote the surveillance level of teachers, three things need to be done as follows: firstly, as was discussed above, teachers should change their roles from instructor, judger and examiner to guider, partner and participator; secondly, they can conduct effective surveillance on students through some surveillance modules on IMITS; thirdly, they can further develop the module of question ask and answer on IMITS to get to know the status quo of students' autonomous learning.

\section{Strategies Concerning Student}

To promote the information quality of students: Considering the above-mentioned problems concerning students in their web autonomous learning of English, the key to improve the effects of learning is to promote their information quality, which consists of the following five abilities: the ability to use modern education technology to process information which includes data digging technology, web technology and search engine technology; the ability to acquire and combine information which means students are able to get the information they need and categorize them so as to establish their own knowledge system; the ability to convert and assess information which requires students to make a critical analysis of the information they've got and digest them; the ability to apply information which means students are able to apply the acquired information in their practice to solve problems; the ability to filtrate information which enables students to voluntarily resist the distractions of some rubbish information on the web and pick out the information they really need.

To strengthen the training on students' autonomous learning strategies: A lot of problems have been revealed through investigation concerning students' autonomous learning strategies, which indicates it is a must to carry out suitable training on learning strategies for students. Concerning college English learning through IMITS, the training should focus on the four basic language skills of listening, speaking, reading and writing. Only when students are competent enough in the four skills, can their autonomous learning of English be fruitful.

To perfect the assessment system for students' autonomous learning: Assessment is of vital importance in the process of students' autonomous learning, which goes through the whole process of learning. The goal of assessment is to surveil the autonomous learning process of learners and make effective feedback to them so as to guarantee their learning quality. The assessment system consists of diagnostic assessment, formative assessment and summative assessment. Diagnostic assessment is made at the beginning of learning to determine the starting level of learners and the suitable teaching schedule, strategy accordingly; formative assessment is made during the process of learning to evaluate the status quo of learners in 
the aspects of emotion, attitude and learning strategies; diagnostic assessment is made at the end of learning to check whether the goal of teaching is achieved or not, which usually takes the form of mid-term or final examination.

\section{CONCLUSION}

IMITS, after advocated by Department of Education to assist college English teaching reform, has triggered great changes in college English teaching in Chinese universities and colleges nowadays. This paper, based on the actual situation of applying IMITS in college English teaching in our university, has successfully demonstrated the advantages and problems of IMITS teaching, and more importantly, proposed some corresponding strategies to solve the problems. With all the data shown above, a conclusion can be made that IMITS, as an effective option to improve the quality of college English teaching, still has some problems. Only when all the problems are properly solved, can IMITS exert it effect to the maximum in realizing individualized, autonomous learning and improving the cultivation of students' communicative competence in English. As more and more universities and colleges are applying IMITS in their college English teaching nowadays in China, the issues discussed in this paper might serve as a guideline for them in the practice.

\section{REFERENCES}

[1] C. Q. Lang and J. Zeng, "A Probe into the Cultivation of Learner Autonomy of Foreign Language Learners in China", Foreign Language World, vol. 102, no. 4, pp. 24-30, 2004.

[2] J. F. Xu, "An Investigation and Analysis of Autonomous English Learning Ability for Non-English Major College Students", Foreign Language Teaching and Research, vol. 36, no. 1, pp. 64-68, 2004.

[3] L. Zhao, Teaching Design and Construction of Process Mode for College English Teaching, Beijing: Foreign Language Teaching and Research Press, 2005.

[4] Ministry of Education of China, College English Curriculum Requirements, Beijing: Foreign Language Teaching and Research Press, 2007.
[5] P. Liu and J. Qin, "Teacher's Guide, Supervision and Management on Web-based Autonomous Learning", Computer-Assisted Foreign Language Education, vol. 118, no. 6, pp. 63-67, 2007.

[6] M. Zhang, "A Probe into College English Teaching based on Web Teaching Platform", Journal of Xingtai University, vol. 26, no. 4, pp. 97-99, 2011.

[7] W. Yu, "General Principle of Web Courseware Interface Design", Information Technology Education of China, vol. 17, no. 7, pp. 45-51, 2008.

[8] X. Chen, "Computer Aided Teaching in The Application of Teaching Chinese as A Foreign Language", JCIT: Journal of Convergence Information Technology, vol. 8, no. 5, pp. 652-660, 2013. http://dx.doi.org/10.4156/jcit.vol8.issue5.75

[9] J. T. Zhai, G. J. Liu and Y. W. Dai, "Detection of FTP Covert Channel Based on Markov Model", IJACT: International Journal of Advancements in Computing Technology, vol. 4, no. 17, pp. 410-417, 2012. http://dx.doi.org/10.4156/ijact.vol4.issue17.48

[10] F. Al-saif and A. Gauthaman, "The Management of E-learning at University of KKU, Abha", IJET: International Journal of Emerging Technologies in Learning, vol. 8, no. 1, pp. 4-9,2013.

[11] S. R. Wang, "On the Revision of College English Curriculum Requirements", Foreign Language of China, vol. 5, no. 1, pp. 4$10,2008$.

[12] L. F. Wen, "A Study on the Internet-based Multi-dimensional English Teaching Mode", Journal of Social Science of Hunan Medical University, vol. 11, no. 2, pp. 169-171, 2009.

[13] B. B. Cao, "Reform in College English Teaching-CAI", Journal of Baoshan Teacher's College, vol. 25, no. 6, pp. 94-96, 2006.

[14] Q. F. Wen, Study on English Learning Strategies, Shanxi: Shanxi Normal University Press, 2003.

\section{AUTHORS}

Zhang Wenming is with Anhui Polytechnic University, Wuhu 241000 China (13956183660@163.com).

Zhang Erwen is with Anhui Polytechnic University, Wuhu 241000 China (zhangerwen81@163.com).

This work was supported in part by key project of Humanities and Social Sciences, Anhui Educational Commission under Grant 2011sk204zd and the teaching and research project of Anhui Polytechnic University under Grant 2010xjy35. Manuscript received 19 April 2013. Published as resubmitted by the authors 02 June 2013 . 